\title{
Evaluation of sodium valproate levels in malnourished childhood epilepsy and its consequences
}

\author{
Vishwanath Reddy Gampala', Sampath Raj Peraboina', Sudhakar Ajmeera², \\ Sirisha Kalam ${ }^{3}$, Nagesh Adla', Goverdhan Puchchakayala' \\ ${ }^{1}$ Department of Clinical Pharmacy, Vaagdevi College of Pharmacy, Warangal, Telangana State, India \\ ${ }^{2}$ Associate Professor, Department of Pediatrics, Kakatiya Medical College, MGM Hospital, Warangal, \\ Telangana State, India \\ ${ }^{3}$ Head of the Department, Department of Analysis, Vaagdevi College of Pharmacy, Warangal, \\ Telangana State, India
}

\begin{abstract}
Objectives. To measure and compare free fraction of serum levels of VPA (valproic acid) between non-malnourished and malnourished epileptic children and to evaluate the adverse effects (myopathy, hepatotoxicity).

Material and methods. It is a prospective comparative observational case control study in which forty epileptic children (malnourished: 18 male/8 female, age $8.3 \pm 2.5$, non-malnourished: 8 male/6 female, age $8.1 \pm 2.1$ ) who fulfilled the inclusion criteria were recruited as study group and twenty children as control group (12male/8 female, age $6.0 \pm 2.8$ ). Outcome measures monitored are serum VPA levels (total and free fraction of serum VPA), serum CK (creatinine kinase), SGOT (serum glutamic oxaloacetic transaminase) and SGPT (serum glutamic pyruvic-transaminase). Using screening tool for the assessment of malnutrition in pediatrics (STAMPC), subjects are categorized into mild, moderate, severe malnourished as $-1 \mathrm{SD},-2 \mathrm{SD},-3 \mathrm{SD}$ respectively

Outcomes. There is an elevation in mean free fraction of VPA is $17.3 \pm 6.4 \mu \mathrm{g} / \mathrm{ml}$ whereas in non-malnourished group it was found to be $8.7 \pm 4.2 \mu \mathrm{g} / \mathrm{ml}$ with $\mathrm{P}=<0.001$. While mean total drug concentration in malnourished and non-malnourished was found to be $88.6 \pm 49.9 \mu \mathrm{g} / \mathrm{ml}, 70.8 \pm 33.9 \mu \mathrm{g} / \mathrm{ml}$ respectively. Mean CK, SGOT, SGPT in control is 29.3 $\pm 9.9 \mathrm{IU} / \mathrm{L}, 28.5 \pm 5.4 \mathrm{IU} / \mathrm{L}, 24.5 \pm 4.2 \mathrm{IU} / \mathrm{L}$ respectively. whereas mean CK, SGOT, SGPT in malnourished subjects is $16.9 \pm 9.1 \mathrm{IU} / \mathrm{L}, 28.8 \pm 8.5 \mathrm{IU} / \mathrm{L}, 25.9 \pm 9.1 \mathrm{IU} / \mathrm{L}$ Correspondingly .while Mean CK, SGOT, SGPT in non-malnourished individuals is $15.7 \pm 11.3 \mathrm{IU} / \mathrm{L}, 32.4 \pm 8.8 \mathrm{IU} / \mathrm{L}, 28.7 \pm 7.8 \mathrm{IU} / \mathrm{L}$ respectively. No correlation was observed between elevated serum drug concentrations, clinical response and side effects.

Conclusion. We observed that clinical response and side effects are serum concentration independent hence our research make unnecessary to monitor serum drug concentration for every individual and drug monitoring should be restricted to subjects with severe ADR's. Our data also suggest Valproate unveiled mitochondrial myopathy is limited to subgroup of population.
\end{abstract}

Keywords: sodium valproate, malnutrition, adverse effects, free fraction of drug

FUNDING: This work was funded by the management of Vaagdevi College of Pharmacy, Rajaji Nagar, Ramnagar, Hanamkonda, Telangana 506001, India.

\section{INTRODUCTION}

Sodium valproate is the most commonly used drug in pediatrics with epilepsy because of its low toxic profile and broad spectrum of activity against different kind of seizures (1). It is a highly protein bound (78-94\%) with time to peak level of 3-6 hours, half-life of about 11-20 hours and time to attain steady state concentration of 2-4 days (2). There is a decrease in plasma proteins which is a common feature of hypoproteinemia in malnourished children. (3) which in turn increases volume of distribution $(\mathrm{Vd})$ of sodium valproate. 
Therapeutic drug monitoring (TDM) studies have demonstrated no correlation between dose administered with serum levels of VPA and also with clinical response $(4,5)$. Toxic effects like sedation, depigmentation of hair and hair loss were seen when the serum VPA levels exceed $600 \mu \mathrm{mol} / 1$ (5). In a VPA intoxication case report there is an escalation of SGOT, SGPT and CK in whom plasma levels of VPA was found to be very high (9064.4 $\mu \mathrm{mol} / \mathrm{L})(6)$. There is a deficiency of data correlation between serum VPA levels SGOT and SGPT levels, our work is aimed to fulfill this deficiency.

It is well known that sodium valproate is an enzyme inducer and it cause escalation of SGOT, SGPT levels. Zimmerman et al. has reported valproate induced hepatotoxicity in twenty three patients which shows an elevation in SGOT and SGPT levels which is due to metabolites (7). In a review by Jeavons et al. have reported hepatotoxicity in eighty eight patients who are on sodium valproate which is most likely to appear within six months on start of therapy (8).

A review by Pasnoor et al. have shown the possible drugs and their pathologic mechanism's effecting myopathy (9). Various review articles also delineated about drug induced myopathies which have stated that there is a marked elevation of serum CK in myopathy (10-12). Some case reports show elevation of serum CK on treatment with sodium valproate. Some of them suggest it is because sodium valproate triggers the carnitine type- 2 deficiency which is the transporter of long chain fatty acids in to the inner membrane of mitochondria which leads to energy depletion in mitochondria of muscle cells by which muscle cells are subjected to rhabdomyolysis in which elevation of CK is seen $(13,14)$. Since there is an increase of free fraction of VPA in malnourished condition free VPA levels may show severe impact on carnitine levels that may increase the risk of myopathy. A case report by Chaudhry, et al. has shown elevation of CK in a 12 year old boy with MELAS (Mitochondrial Myopathy, Encephalopathy, Lactic acidosis and Stroke like episodes) (15). A study in forty one epileptic children shown a significant decrease in serum carnitine levels which does not correlate with SGOT and SGPT levels (16). Similar study in 50 children have shown no correlation between serum VPA levels and serum carnitine levels but have shown significant correlation between VPA levels and muscle carnitine levels (17). Three case reports were also discussed by Uppin, Megha S. et al. which states that among two patients there is an improvement in serum CK levels on treatment with levocarnitine (18). A case report has shown elevation of CK due to sodium valproate overdose, (6) which may happen in malnourished children due to increase in fraction of free drug concentration in plasma.

We believe in the hypothesis that free drug concentration of valproate is going to increase in malnourished patients which in turn effects the enzymes like CK, SGOT and SGPT. Because of the scarcity of data about VPA concentration in malnutrition population whose prevalence is more in countries like India our work is focused to fulfill the scarcity and safety monitoring in this subset population. Hence the present work is aimed to study the effect of malnutrition on drug concentration and to study how the elevated drug concentration will affect the CK, SGOT and SGPT and finally to compare the results obtained between healthy and malnutrition patient.

\section{MATERIAL AND METHODS}

\section{Subjects}

This is a prospective comparative case control study. Control group was included because deficiency of sufficient data on normal range of CK in Indian pediatric population. Study was conducted at Mahatma Gandhi Memorial Hospital which is a 1,000 bedded teaching government hospital and is one of the biggest hospital in Telangana state. Patients who meet the inclusion criteria were recruited for a period of two months that is in the month of August and September of 2016 from pediatric inpatient department.

Subjects who are diagnosed with epilepsy by the physician and who are on sodium valproate 400 $\mathrm{mg}$ /day for a minimum of one month were recruited for the study as per the guidelines of declaration of Helsinki. Using screening tool for the assessment of malnutrition in pediatrics $\left(\right.$ STAMP $^{\circ}$ ), subjects are categorized into mild, moderate, severe malnourished as $-1 \mathrm{SD},-2 \mathrm{SD},-3 \mathrm{SD}$ respectively. Subject details were collected in data collection form which includes age, gender, anthropometric 
parameters, duration of treatment, number of seizure episodes, side effects experienced if any and list of other medications.

Inform consent form is signed from the guardians of the subjects. Samples were collected from the venous blood ( $2 \mathrm{ml}$ from each participant) after 3 hours of oral administration, however subjects with recent seizure episodes were excluded from the study because of elevated CK which may last 3 to 8 days (19) number of seizure episodes were tracked by interviewing the guardians of children and adverse effects are monitored by examining present and past medication charts of the patients. Subjects with conditions like hypothyroidism, hyperthyroidism, who underwent resent surgery or trauma, patients on other myopathy inducing drug (except study drugs), hepatic or renal disease, (20) patients who are newly prescribed on sodium valproate were also excluded. Samples were collected in to Eppendorf tubes which are centrifuged at $4,000 \mathrm{rpm}$ and stored at $-20^{\circ} \mathrm{C}$ to measure free fraction of VPA. $1 \mathrm{ml}$ of the blood sample was collected in to amicon tubes and centrifuged at 4,000 rpm for protein separation and obtained clear liquid is stored at $-20^{\circ} \mathrm{C}$. No deterioration of the samples were seen during the time of analysis. CK, SGOT, SGPT levels were analyzed on the same day of the sample collection whereas serum free fraction VPA levels were measured within one month of sample collection.

\section{Data assessment}

Serum levels of free fraction sodium valproate was determined by HPLC-UV method which was developed by kishor et al. (21) equivalent amount of acetonitrile with $2.5 \mu \mathrm{g}$ diazepam as an internal standard is added to the serum for protein precipitation and mixed on the Cyclomixer which is then centrifuged at $4000 \mathrm{rpm}$ for 10 minutes $20 \mu 1$ of the supernatant is injected using Hamilton injection in to HPLC with running time of 10 minutes. Chromatograms of the individual subjects were recorded and saved. This method was carried out on Shimadzu HPLC using C-18 column at $50^{\circ} \mathrm{C}$ using acetonitrile and $0.05 \mathrm{M}$ phosphate buffer $(\mathrm{pH} 3.0)$ $45: 55$ as a mobile phase at a flow rate of $1.2 \mathrm{ml} /$ $\min$.

Creatinine kinase, SGOT and SGPT levels were determined calorimetrically using Turbochem-100 auto analyzer.

\section{Statistical analysis}

Statistical analysis were carried out by using SPSS 20.1 for windows, our data is within the skewness hence analysis were performed on parametric data. Descriptive statistics like mean, standard deviation were calculated for each outcome measurement. Outcome of each measurement was correlated by using Pearson's correlation. Serum VPA levels were compared by two independent sample $t$ test by setting level of significance at 0.05 .

TABLE 1. Distribution of all variables in control and epilepsy groups

\begin{tabular}{|c|c|c|c|c|}
\hline \multirow{2}{*}{ Characteris cs } & \multirow{2}{*}{$\begin{array}{l}\text { Control } \\
(n=20)\end{array}$} & \multicolumn{2}{|c|}{ Epilepsy pa ents } & \multirow[b]{2}{*}{$P$ value } \\
\hline & & $\begin{array}{c}\text { Without } \\
\text { malnutri on }(n=14)\end{array}$ & $\begin{array}{l}\text { With malnutri on } \\
(n=26)\end{array}$ & \\
\hline Age, mean(SD) & $6.0(2.8)$ & $8.1(2.1)$ & $8.3(2.5)$ & - \\
\hline Height, mean (SD) & $114.8(15.9)$ & $128.2(22.0)$ & $119.5(15.0)$ & - \\
\hline Weight, mean (SD) & $21.4(6.8)$ & $28.1(10.7)$ & $19.8(5.2)$ & - \\
\hline Gender, Male (\%) & $12(60.0)$ & $8(57.1)$ & $18(69.2)$ & - \\
\hline Female (\%) & $8(40.0)$ & $6(42.8)$ & $8(30.7)$ & - \\
\hline Head Circumference, mean (SD) & $49.4(4.6)$ & $50.5(2.6)$ & $47.5(8.8)$ & - \\
\hline Midd upper arm & & & & \\
\hline circumference, mean (SD) & $20.7(4.5)$ & $20.2(3.2)$ & $16.5(3.6)$ & - \\
\hline Consanguinity, Yes (\%) & $0(0)$ & $6(42.9)$ & $6(23.1)$ & - \\
\hline No (\%) & $20(100.0)$ & $8(57.1)$ & $20(76.9)$ & \\
\hline Developmental delay, Yes (\%) & $0(0)$ & $0(0.0)$ & $6(23.1)$ & \\
\hline No (\%) & $20(100.0)$ & $14(100.0)$ & $20(76.9)$ & - \\
\hline Free VPA, mean (SD) & - & $8.7(4.2)$ & $17.3(6.4)$ & $<0.001^{* *}$ \\
\hline Total VPA, mean (SD) & - & $70.8(33.9)$ & $88.6(49.9)$ & 0.003 \\
\hline Serum CK. Mean (SD) & $29.3(9.9)$ & $15.7(11.3)$ & $16.9(9.1)$ & $<0.001^{*}$ \\
\hline SGOT, mean (SD) & $28.5(5.4)$ & $32.4(8.8)$ & $28.8(8.5)$ & $0.187^{*}$ \\
\hline SGPT, mean (SD) & $24.5(4.2)$ & $28.7(7.8)$ & $25.9(9.1)$ & $0.176^{*}$ \\
\hline
\end{tabular}

\footnotetext{
${ }^{* *}$ Two independent sample $t$ test
}

* One way ANOVA 
SGOT, SGPT and CK were compared by one way ANNOVA. Histograms were visually analyzed to conform the distribution of the variables (Table 1).

\section{RESULTS}

A total of 76 subjects were screened in the study who are between 2 to 12 years of age, out of whom 20 are control and remaining forty who meet the inclusion criteria were included, among them 26 are with malnutrition and remaining 14 are non-malnutrition. 16 patients who do not meet the requirements of inclusion criteria were excluded. This is illustrated in flowchart 1. Mean age of control group is $6.0 \pm 2.8$ years whereas mean age in group without malnutrition is $8.1 \pm 2.1$ years, 8.32 .5 years in malnourished children.

When compared with non-malnourished subjects peak heights and peak areas are significantly elevated in malnourished individuals which are illustrated in Fig. 1, 2, 3.

No correlation was seen between serum VPA levels and SGOT, SGPT, levels but there is a moderate negative correlation between serum VPA levels and CK $(\mathrm{p}<0.001)$.

10 non-malnourished and 16 malnourished children have shown an improvement in clinical outcome (decreased number of seizures from the be- ginning of treatment), while 4 subjects in non-malnourished and 10 in malnourished have experienced recurrence of seizures and experienced poor clinical outcome, which is no decrease in number of seizure frequencies. Among the improved group 6 subjects have their free serum VPA levels in therapeutic range, 12 subjects have sub-therapeutic levels and 8 subjects have above the therapeutic levels of VPA. Among the group with poor clinical outcome 2 subjects have free serum VPA levels within the therapeutic range, 6 are with sub-therapeutic levels and 6 are with above the therapeutic levels.

30 percent of the treatment group experience muscle pains, 10 percent experience headache, 5 percent have complained about weight gain, another 5 percent complained about anorexia while 50 percent of the treatment group did not complained about any symptoms. When duration is considered muscle pain is the prominent complain among the children who are on valproate for longer duration (Fig. 4).

\section{DISCUSSION}

Our work determine that clinical outcome is independent to that of serum drug concentration which have been demonstrated in previous studies

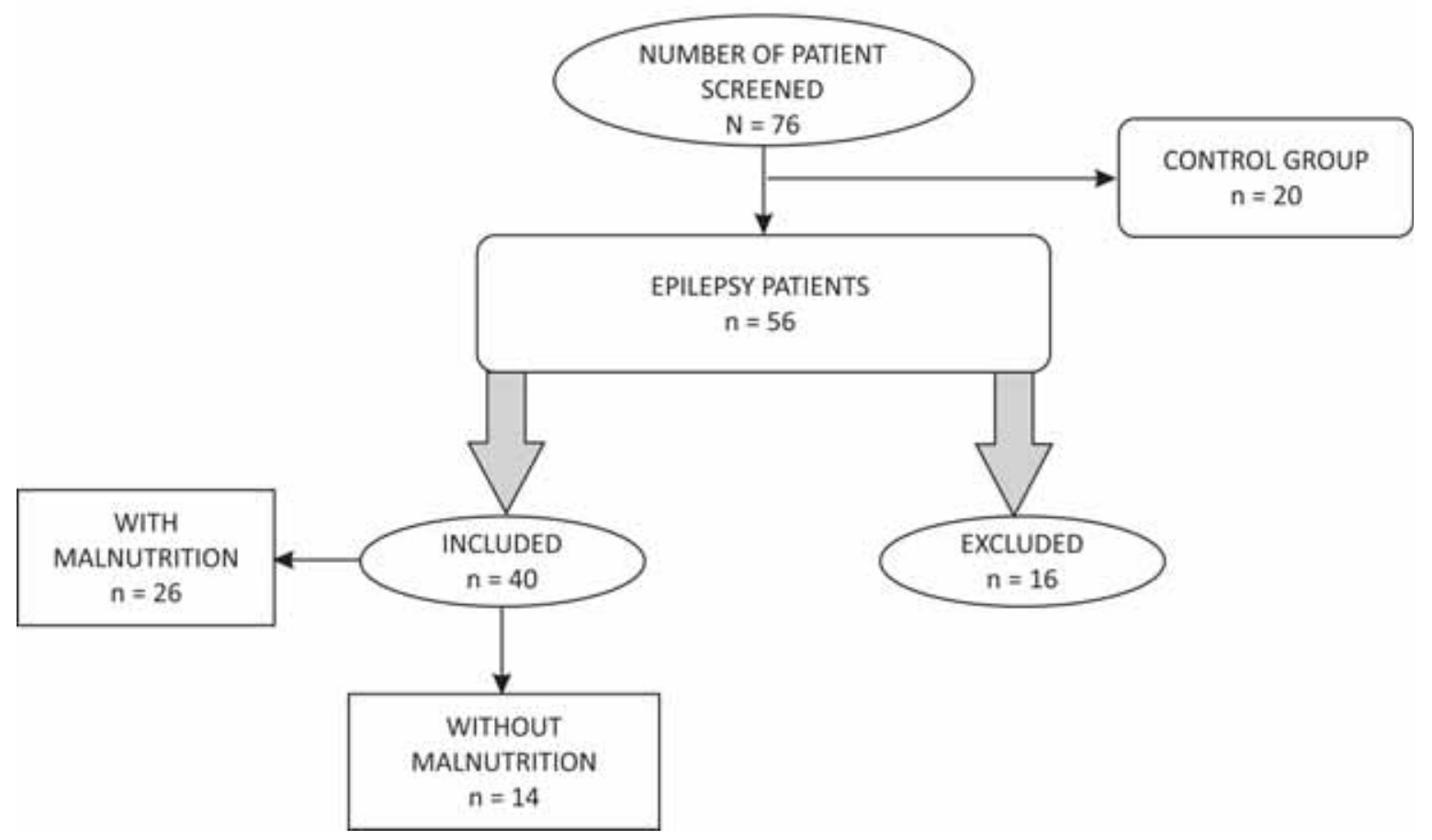

Flowchart 1. Recruitment procedure and number of patients in each groups 


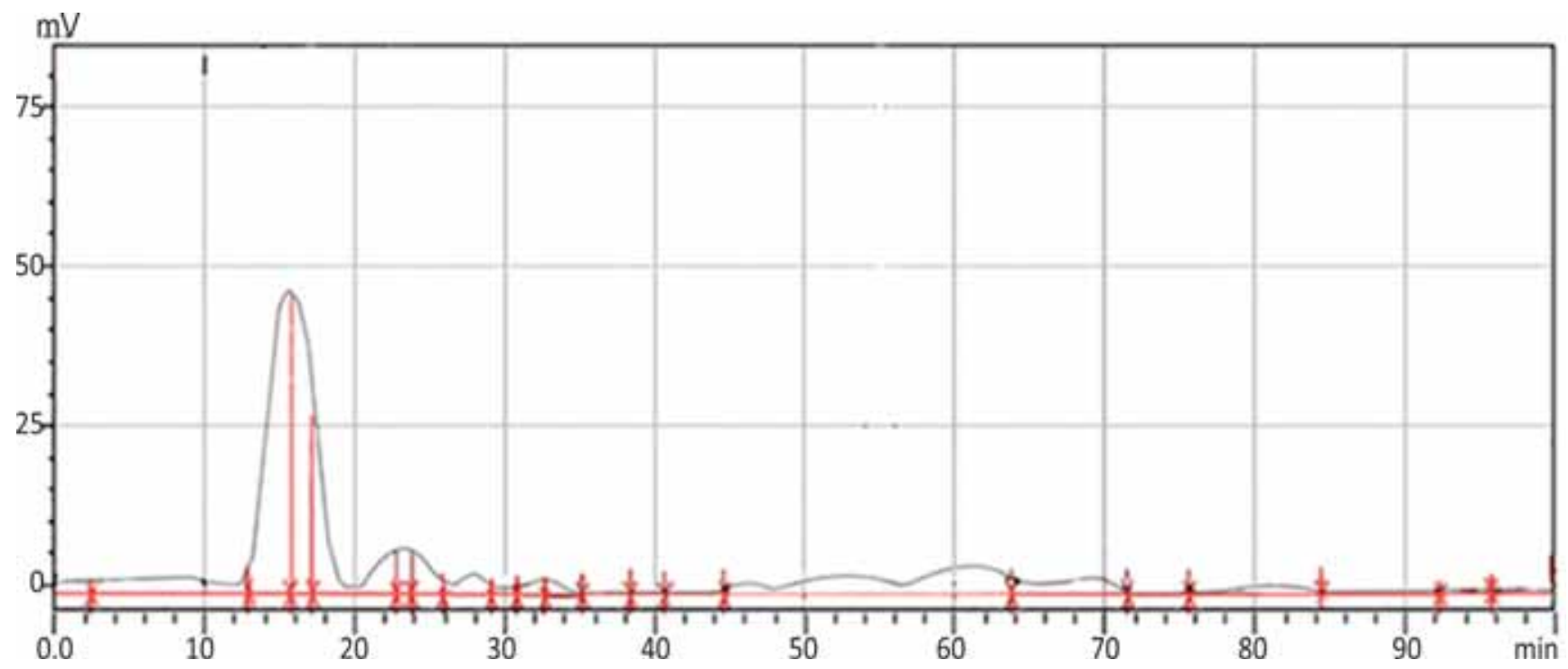

FIGURE 1. Chromatogram of blank serum

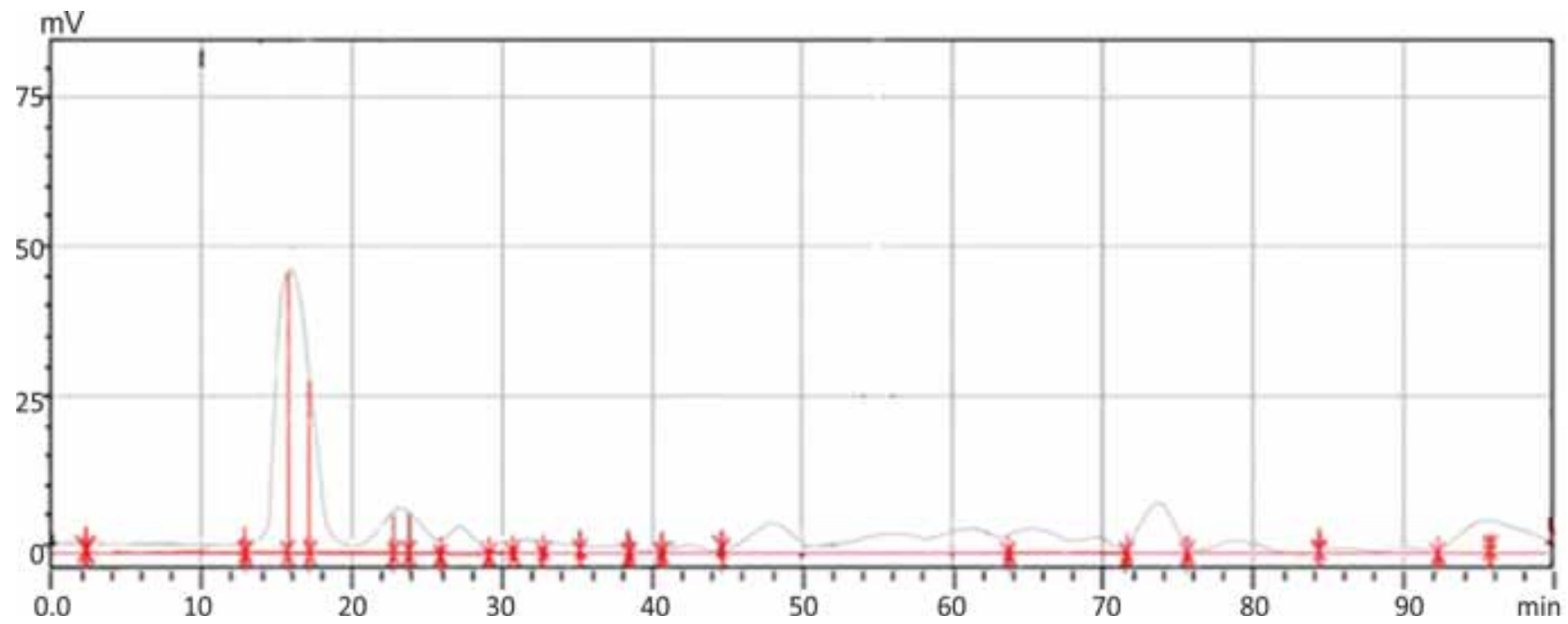

FIGURE 2. Chromatogram of without malnutrition patient

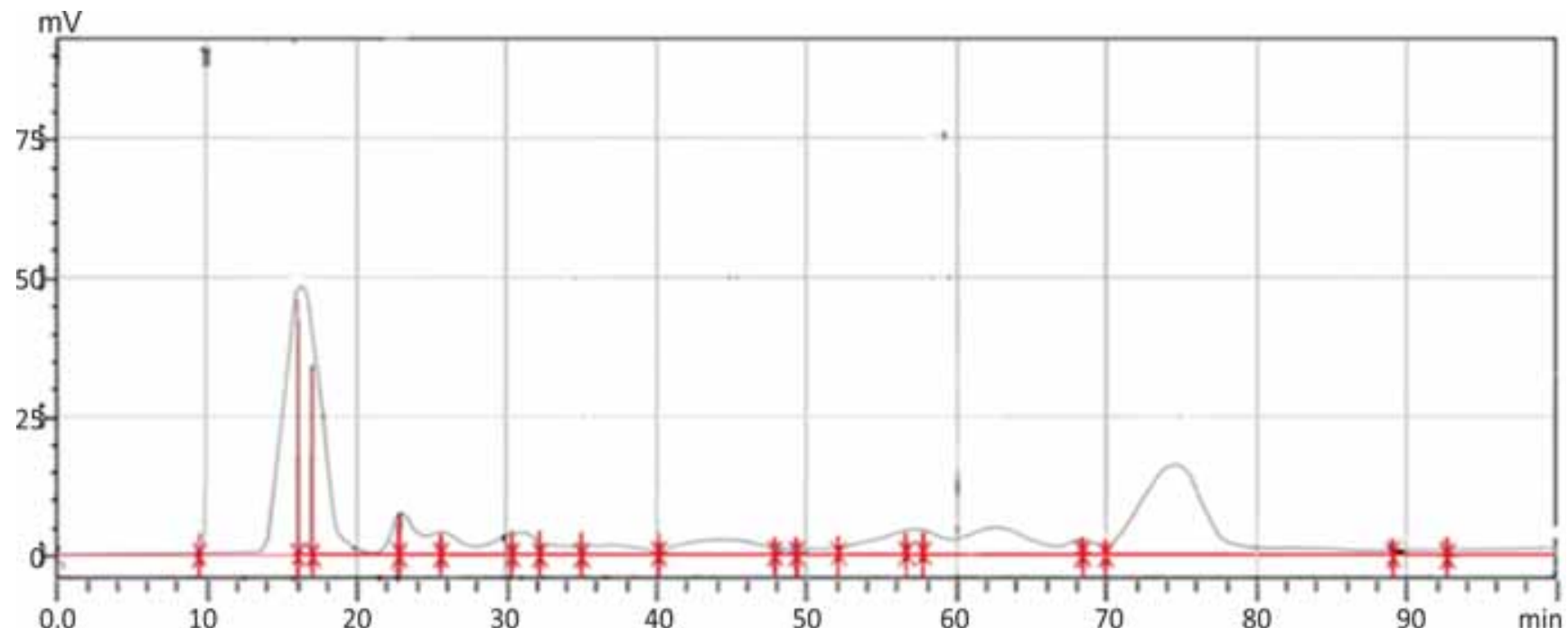

FIGURE 3. Chromatogram of malnourished patient 


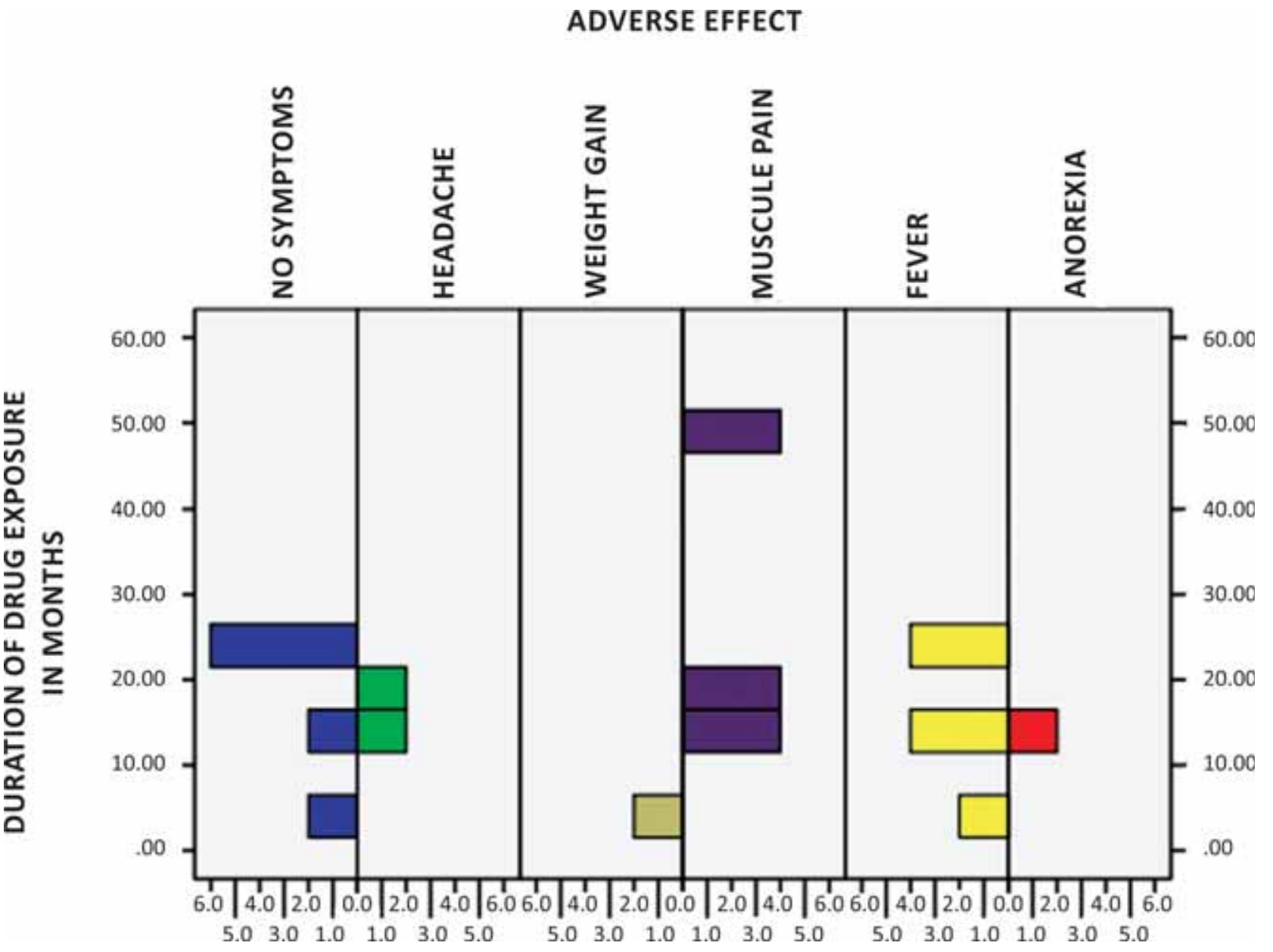

FIGURE 4. Duration with ADRs

(4). Many TDM studies were conducted before but none of them had monitored malnourished pediatric population which is novel in our work. TDM in malnourished children is essential in countries like India where prevalence is more (22). Through which individualization of dose is achieved and side effects are minimized. Although our study spectacle that there is an improvement in seizures we did not find any relation between serum drug levels and clinical control. From HPLC chromatograms we observed escalation of mean free serum VPA in malnourished subjects as predicted. We suspected that side effects are dependent on free serum VPA for which we monitored the SGOT, SGPT and CK levels and correlated with free serum VPA concentration. But our results are contrary to what we expected, no significant correlation was seen between serum VPA concentration with CK, SGOT, SGPT and also side effects.

Our findings espouses that VPA induced myopathy is limited to a subgroup of population $(15,23,24)$. The outcome of our study is contradictory to previ- ously reported case studies in which there is a rise in serum CK levels in study subjects who were on VPA. But our results show that there is a decrease in mean serum CK levels malnourished group and compared with controlled group, which might be because of pathological changes in malnutrition (25). Nevertheless our results suggest there is a reduction of $\mathrm{CK}$ in without malnutrition group which may be due to effect of valproate on muscles.

The possible bias in our study include postictal elevations of serum CK and exercise induced CK elevations which are precluded by excluding such kind of patients (19).

Chaudhary et al. in her case report discussed about mitochondrial myopathy which is unveiled by VPA therapy which had shown that there is an elevation of $\mathrm{CK}$ and precipitation of seizures on starting valproate therapy (15). In this report the elevation of CK might not be because of Valproate it might be due to postictal episode. Another case reported by Alexandros et al. had shown CK elevation without seizure episode (26). These cases are 
the source of bias that the Valproate therapy is the sole cause for CK elevations.

Limitations of our study include short duration of study, single sample collected and evaluated from the individual participant, lack serum carnitine levels, lack of EMG (Electromyography) and muscle biopsy examinations, which might be needed in further studies to confirm the hypothesis.

Studies in malnutrition children is extensively recommended because of its prevalence in countries like India (22), among whom the possibility of epilepsy is much higher. Kinetic parameters among this population increases the risk of developing drug toxicity by increasing free plasma drug concentration.

In this work we observed an increase in mean free drug concentration in malnourished subjects when compared with healthy individuals. No correlation was seen between elevated free serum drug concentrations, clinical response and side effects hence we conclude that side effects and clinical response is dose independent which was been reported in previous investigations.

\section{CONCLUSION}

Our research makes unnecessary to monitor serum drug concentration for every individual and drug monitoring should be restricted to subjects with severe ADR's or with mitochondrial disorders.

Our data suggest Valproate unveiled mitochondrial myopathy is limited to subgroup of population. It also suggest further studies which include serum drug concentration, biopsy studies, plasma carnitine levels along with $\mathrm{CK}$ at multiple intervals in inpatient setup is needed to conform myopathy associated with sodium valproate.

\section{ACKNOWLEDGEMENT}

The authors are obliged to the management of Vaagdevi College of Pharmacy for funding and supporting our work, staff nurse Madhavi, Sumalatha and Avanthi for their support in pediatric department. We are thankful to J Anvesh, N Ravinder Reddy, M. Ramakrishna of analysis department for their contribution in this work. We are also thankful to G Sudhir Kumar and G Pavani pharm-D students of department of clinical pharmacy for their valuable suggestion's. We are grateful to the participants and their guardians for voluntarily taking part in this work.

PATIENT CONSENT: obtained from their respective guardian.

\section{Conflict of interest: none declared}

\section{REFERENCES}

1. Bruni J., Wilder B.J. Valproic acid: Review of a new antiepileptic drug. Archives of neurology. 1979 Jul 1; 36(7):393-8.

2. Johannessen S.I. Therapeutic drug monitoring of antiepileptic drugs. Handbook of Analytical Separations. 2004 Dec 31; 5:221-53.

3. Oshikoya K.A., Senbanjo I.O. Pathophysiological changes that affect drug disposition in protein-energy malnourished children. Nutrition \& metabolism. 2009 Dec 1; 6(1):1.

4. McQueen J.K., Blackwood D.H., Minns R.A., Brown J.K. Plasma levels of sodium valproate in childhood epilepsy. Scottish medical journal. 1982 Oct 1; 27(4):312-7.

5. Henriksen O., Johannessen S.I. Clinical and pharmacokinetic observations on sodium valproate-A 5-year follow-up study in 100 children with epilepsy. Acta Neurologica Scandinavica. 1982 May 1; 65(5):504-23.

6. Sikma M., Mier J.C., Meulenbelt J. Massive valproic acid overdose, a misleading case. The American journal of emergency medicine. 2008 Jan 31; 26(1):110-e3.

7. Zimmerman H.J., Ishak K.G. Valproate-Induced Hepatic Injury: Analyses of 23 Fatal Cases. Hepatology. 1982 Sep 1;2(5).

8. Jeavons P.M. Non-dose-related side effects of valproate. Epilepsia. 1984 Jun 1; 25(s1):S50-5.

9. Pasnoor M., Barohn R.J., Dimachkie M.M. Toxic myopathies. Neurologic clinics. 2014 Aug 31; 32(3):647-70.

10. Guis S., Mattéi J.P., Lioté F. Drug-induced and toxic myopathies. Best Practice \& Research Clinical Rheumatology. 2003 Dec 31; 17(6):877-907.

11. Le Quintrec J.S., Le Quintrec J.L. Drug-induced myopathies. Bailliere's Clinical Rheumatology. 1991 Apr 30; 5(1):21-38.

12. Bannwarth B. Drug-induced myopathies. Expert opinion on drug safety. 2002 May 1; 1(1):65-70.

13. Kottlors M., Jaksch M., Ketelsen U.P. Weiner S., Glocker F.X., Lücking C.H. Valproic acid triggers acute rhabdomyolysis in a patient with carnitine palmitoyltransferase type II deficiency. Neuromuscular Disorders. 2001 Nov 30; 11(8):757-9.

14. Ahmed R. Sodium valproate-induced myopathy in a child. Sultan Qaboos University medical journal. 2015 Feb; 15(1):e146.

15. Chaudhry N., Patidar Y., Puri V. Mitochondrial myopathy, encephalopathy, lactic acidosis, and stroke-like episodes unveiled by valproate. Journal of pediatric neurosciences. 2013 May 1; 8(2):135..

16. Chung S., Choi J., Hyun T., Rha Y., Bae C. Alterations in the carnitine metabolism in epileptic children treated with valproic acid. Group. 1997 Dec 1; 77(5.55):67-8.

17. Anil M., Helvaci M., Ozbal E., Kalenderer O., Anil A.B., Dilek M. Serum and muscle carnitine levels in epileptic children receiving sodium valproate. Journal of child neurology. 2009 Jan 1; 24(1):80-6. 
18. Uppin M.S., Sundaram C., Meena A.K., Reddy K.M., Reddy K.K., Vanniarajan A., Thangaraj K. Lipid storage myopathies with unusual clinical manifestations. Neurology India. 2008 Jul 1; 56(3):391.

19. Brigo F., Igwe S.C., Erro R., Bongiovanni L.G., Marangi A., Nardone R., Tinazzi M., Trinka E. Postictal serum creatine kinase for the differential diagnosis of epileptic seizures and psychogenic non-epileptic seizures: a systematic review. Journal of neurology. 2015 Feb 1; 262(2):251-7.

20. Smithson J. Drug induced muscle disorders. Australian Pharmacist. 2009 Dec; 28(12):1056.

21. Kishore P., Rajani Kumar V., Satyanarayana V., Krishna D.R. HPLC determination of valproic acid in human serum. Die Pharmazie-An International Journal of Pharmaceutical Sciences. 2003 Jun 1; 58(6):378-80.
22. Bhutia D.T. Protein energy malnutrition in India: the plight of our under five children. Journal of family medicine and primary care. 2014 Jan 1; 3(1):63.

23. Lam C.W., Lau C.H., Williams J.C., Chan Y.W., Wong L.J. Mitochondrial myopathy, encephalopathy, lactic acidosis and stroke-like episodes (MELAS) triggered by valproate therapy. European journal of pediatrics. 1997 Jun 1; 156(7):562-4.

24. Kasturi L., Sawant S.P. Sodium valproate-Induced skeletal myopathy. The Indian Journal of Pediatrics. 2005 Mar 1; 72(3):243-4.

25. Balmer S.E., Rutishauser I.H. Serum creatine kinase in malnutrition. The Journal of pediatrics. 1968 Nov 30; 73(5):783-7.

26. Papadimitriou A., Servidei S. Late onset lipid storage myopathy due to multiple acyl CoA dehydrogenase deficiency triggered by valproate. Neuromuscular Disorders. 1991 Dec 31; 1(4):247-52. 